\title{
Replies to Kirk Ludwig and Alexander Miller
}

\author{
CLAUDINE VERHEGGEN York University
}

ABSTRACT: This paper is a reply to Kirk Ludwig's and Alexander Miller's comments on the first part of Donald Davidson's Triangulation Argument: A Philosophical Inquiry. It addresses concerns Ludwig expresses about the triangulation argument's success in establishing the social character of language and thought. It answers Miller's invitation to compare Davidson's non-reductionism with that of Crispin Wright, as well as the social aspect of Davidson's view with the social aspect of Saul Kripke's. And it addresses Miller's worries concerning my claims about the normativity of meaning.

RÉSUMÉ : Cet article est une réponse aux commentaires de Kirk Ludwig et d'Alexander Miller sur la première partie de Donald Davidson's Triangulation Argument: A Philosophical Inquiry. Il répond aux objections de Ludwig selon lesquelles l'argument de la triangulation ne réussit pas à établir le caractère social du langage et de la pensée. Il répond à l'invitation de Miller à comparer le non-réductionnisme de Davidson avec celui de Crispin Wright, ainsi que l'aspect social de la thèse de Davidson avec celui de la thèse de Saul Kripke. Il répond enfin aux questions de Miller concernant mes affirmations sur la normativité de la signification.

Keywords: Donald Davidson, triangulation, meaning, normativity, social externalism, Saul Kripke, Crispin Wright

Many thanks to our three critics for their generous and thoughtful comments. I shall address here the comments made on the first part of the book by Kirk Ludwig and Alexander Miller.

Dialogue 59 (2020), 235-253

(C) Canadian Philosophical Association/Association canadienne de philosophie 2020 doi:10.1017/S001221732000013X 


\section{Reply to Ludwig}

1. Ludwig focuses on the triangulation argument itself. I am glad to hear that he thinks Donald Davidson would have approved of my reconstruction of the argument, as it is indeed quite different from that offered by the vast majority of commentators on Davidson (including, as we shall see, significantly, Ludwig himself). I do take myself to be expounding Davidson's views and arguments, but at times also to be developing and defending them further than Davidson himself does. Accordingly, I put much more emphasis than Davidson himself does on there being two problems that must be solved by any would-be thinker and speaker: that of determining the distance of the causes that are supposed in part to provide her basic propositional ${ }^{1}$ thoughts and utterances with meaning, ${ }^{2}$ and that of determining the width or aspect of those causes. I am more careful than Davidson in distinguishing two types of triangulation: one Davidson often calls primitive, which "does not require intensional attitudes"3 and in which non-linguistic creatures can engage, and the other fully linguistic and propositional. ${ }^{4}$ Most importantly, contra most commentators, I also argue, something which admittedly Davidson never makes explicit, that the two tasks that triangulation is supposed to accomplish, viz., determining meanings and yielding the concept of objectivity, are accomplished in tandem. I believe that this makes, not only for a much stronger argument for the essentially social character of language and thought, but also for the vindication of claims that Davidson held all his life, some tentatively argued for, some not, starting well before he introduced the idea of triangulation. These are that all the features that belong to meaning (both of thoughts and of utterances) are essentially public; that the meanings of basic thoughts and utterances are in part determined by what in the world around us cause us to have those thoughts and to produce those utterances; that possession of the concept of objectivity is needed for possession of thoughts and language; and that language is needed for thought. I shall elaborate on this as I address Ludwig's worries, starting with the steps of the triangulation argument.

1 I shall drop 'propositional' in what follows, as Davidson is concerned exclusively with thoughts that have propositional content, the main characteristic of which is their semantic opacity.

2 Following the convention I adopted in the book, I use 'meaning' here even to talk of the content of thoughts, in part as a reminder that it is propositional thoughts with which we are concerned.

3 Davidson, “Comments on Karlovy Vary Papers," p. 292.

4 Primitive triangulation occurs when creatures are reacting simultaneously to each other and to common stimuli in their surroundings, as in Davidson's example of two lionesses trying to catch a gazelle and coordinating their behaviour by watching each other and the gazelle and reacting to each other's reactions ("Externalisms," p. 7). Linguistic triangulation is a subset of interpersonal linguistic communication. 
2. The ultimate goal of the argument is to answer the foundational philosophical question of what it is for us to mean what we do by our utterances and to have the propositional thoughts and attitudes we have. Thus, the triangulation argument concerns the possibility of both thought and language, and not just that of thought, as Ludwig suggests. And there is a good reason for this connection, a reason which is independent of the arguments Davidson gives early on for the connection between language and thought. This is that both words, the elements of language, and concepts, the elements of thoughts, are governed by conditions of correct application. Thus, the fundamental question could be expressed as what it is for words and concepts to be governed by the conditions of correct application they are governed by. ${ }^{5}$ Now, to the main steps of the triangulation argument.

i. Perceptual externalism: "What determines [at least in part] the contents of ... basic thoughts (and what we mean by the words we use to express them) is what [in the world around us] has typically caused similar thoughts." 6

ii. The cause of someone's response to her environment may in fact be "doubly indeterminate: with respect to width, and with respect to distance. The first ambiguity concerns how much [what 'part or aspect'] of the total cause of [a thought or utterance] ... is relevant to [meaning] .... The second problem has to do with the ambiguity of the relevant stimulus, whether it is proximal (at the skin, say) or distal.",7 (Call these problems respectively the aspect problem and the distance problem.)

iii. There is no way the causes of a lifelong solitary creature's - a solitaire's - responses could be isolated, no way to distinguish proximal causes from distal causes, or among several distal causes, of her responses. (Note that the problem is not "one of verifying what objects or events a creature is responding to" but that, for a solitaire, "there can be no answer to the question." ${ }^{\prime}$ ) It is only when a creature has engaged in primitive triangulation that some distal causes can be isolated.

5 That words and concepts are so governed is widely recognized as a platitude, first emphasized by commentators on Saul Kripke's Wittgenstein on Rules and Private Language. See Wright, "Does Philosophical Investigations $§ ~ 258-60$ Suggest a Cogent Argument against Private Language?," among many others.

6 Davidson, "Epistemology Externalized," p. 201. Davidson wrote in 1991 that he had advocated externalism (short, in what follows, for 'perceptual externalism') for "some thirty years" ("Epistemology Externalized," p. 200), but it is only in the writings on triangulation that he addresses the question of typical causes.

7 Davidson, "The Emergence of Thought," pp. 129-130.

8 Davidson, "The Second Person," p. 119. 
iv. Primitive triangulation solves the distance problem, but only in that primitive triangulators can be said to be responding to distal causes, which is not to say that they have any concepts of distal causes. Having concepts requires solving the aspect problem.

v. Even if the distance problem could be solved for a solitaire, that is, even if she could be said to be responding to distal causes, the aspect problem could not be solved. For what could make it the case that she is responding to one rather than another aspect of her environment, that she is now responding to an aspect similar to that to which she previously responded, as "any set of causes whatsoever will have endless properties in common?"

vi. It looks as though the only way out of the above predicament is to have the would-be speaker and thinker herself contribute to the disambiguation of the causes of her responses. That is, the would-be speaker and thinker herself must determine which causes are similar to which.

vii. The would-be speaker and thinker must therefore be able to distinguish between what seems to her to be a similar cause and what is in fact a similar cause, or between correct and incorrect responses, where this distinction is per force objective, i.e., independent of what she thinks it is, for fear of annihilating the distinction. (Thus, even though fixing the causes involves determining which responses are correct or incorrect, this must be done in such a way that subsequent applications of words and concepts are correct or not independently of the speaker or thinker deeming them to be so.)

viii. Therefore (from vi. and vii.), fixing meanings requires possession of the concept of objectivity. One cannot have a language and thoughts without having the concept. (The relation, to be clear, is conceptual, not temporal.)

ix. Linguistic triangulators are in a position to have the concept of objectivity because they are in a position to disagree about features of the environment they are talking about and, most crucially, to resolve their disagreement in a way that does not depend on the mere say of one or the other interlocutor. (This is what gives them the idea of different perspectives on an objective world.)

$\mathrm{x}$. The solitaire could not be in a similar position. She would always have the only say in the resolution of whatever 'disagreement' we might imagine her having with herself. Thus, whatever would seem to her

9 Davidson, “Externalisms," p. 4. 
to be the case would be the case, making it impossible for her responses to be governed by conditions of correctness, and thus making it impossible for her to have a language and thoughts, which we may have granted her for the sake of the argument.

xi. Therefore (from ix. and x.), only someone who has triangulated linguistically could have the concept of objectivity. That is, we can make intelligible the idea of triangulators having both a language and thoughts and the concept of objectivity, but we cannot make intelligible the idea of a solitaire having any of those.

xii. Therefore (from viii. and xi.), we cannot make intelligible the idea of someone having thoughts without having a language.

xiii. Therefore, language and thoughts are essentially social. For us to mean what we do by our words and to have the propositional thoughts and attitudes we have is for us to have used some of our words in linguistic triangular situations, that is, to have fixed their meaning with triangulating interlocutors through regular connections between our utterances and features of the world around us, features that we and our interlocutors have agreed are the features relevant to determining the meanings of our words.

We have seen (viii.) why possession of the concept of objectivity is needed for possession of thoughts and language, and (xii.) why language is needed for thought. The argument for both conclusions seriously improves on Davidson's often-made assertions, which have little else than intuitive appeal. Thus, in support of the first conclusion, he would often simply declare that it makes no sense to say that someone could have concepts, and words to express them, which by nature are meant to classify, but not be "aware of the possibility of misclassification", ${ }^{10}$ or that someone could have a belief without understanding "the possibility of being mistaken." mentators to be unpersuasive. As for the second conclusion, making explicit the role played by the concept of objectivity in the determination of meaning reveals the indispensability of a linguistic social setting for its possession, and thus the necessity of language for thought. However, what of the claim that meaning is essentially public, and what of externalism, which, as Ludwig correctly observes, I take to be the fundamental premise of the triangulation argument?

The only defence Davidson himself gives of the claim that meaning is essentially public is that "what is to be explained is a social phenomenon ... language

10 Davidson, "Responses to Barry Stroud, John McDowell, and Tyler Burge," p. 698.

11 Davidson, "Thought and Talk," p. 170. 
is intrinsically social."12 However, if externalism is vindicated by the triangulation argument in the way I think that it is, so is the publicity claim. Obviously, if externalism is true, and if the causes that determine in part the meanings of someone's thoughts and utterances need to be publicly available, then the publicity claim is true as well. Now, as I see it, externalism is vindicated by the triangulation argument, for the problem the would-be thinker and speaker must solve, that of disambiguating the causes of her responses to the environment, is a problem similar to the problem the internalist would have to solve, that of disambiguating the mental or internal items that are supposed to provide her thoughts and utterances with meaning. For presumably none of those items wear their meaning on their sleeves, or, if they do, the question arises of what makes it the case that they have the meaning they do. So, if only items that are triangulated upon, that is, items to which at least two interlocutors can have simultaneous access, can be disambiguated, then only external factors that are also publicly available could contribute to the determination of meaning. Therefore, because externalism is true, so too is the publicity claim.

3. Here, however, comes Ludwig's first protest: the most fundamental premise of the argument is not externalism but [Determination], according to which the meanings of thoughts and utterances are determined by something. And [Determination] has not been supported. I certainly cannot find any argument for this "premise" in Davidson's writings, though Ludwig is right in saying that the motivation for it could be that meaning is essentially public. As I just argued, this claim in turn can be seen as having been vindicated by the triangulation argument. But the fundamental premise of the triangulation argument, as I construe it, is externalism, which assumes [Determination]. What to do? We could simply go back to Davidson's insistence that meaning is essentially public, and leave it at that. But I think that a better strategy is rather to insist that we take our job to be giving a philosophical, foundational account of meaning. Thus, we are not satisfied with the Cartesian idea that intentionality is fundamental, a brute fact about us that nothing can illuminate. ${ }^{13}$ (At most, according to this view, as Ludwig suggests, we can say something about how linguistic expressions derive their meaning from the intentions with which speakers use their words, but nothing can be said about the intentions themselves.) As Crispin Wright, to whom I shall return, puts it, "it is an important methodological precept that we do not despair of giving answers to constitutive questions too soon." 14 And it is important that we do not despair of giving such answers

12 Davidson, "The Structure and Content of Truth," p. 314.

13 As I argue in Chapter 4 of the book, this assumption is what allows Descartes to get his scepticism about the external world going.

14 Wright, "Wittgenstein's Rule-Following Considerations and the Central Project of Theoretical Linguistics," p. 191. 
even though, like Davidson (and Wright), we think that no reductive answers are forthcoming. I turn to the worry Ludwig expresses after granting [Determination].

4. This, in a nutshell, is that having two individuals, rather than a solitaire, responding to their environment makes no difference; the causes of their responses may be equally ambiguous. I think Ludwig's objection here betrays a misunderstanding of the Davidsonian project and its execution. Ludwig's idea is that we are to consider and compare the patterns of behaviour of a solitaire and those of a pair of individuals (interestingly, he does not call them triangulators) in their environment. We are to do this because it is the only way we can take a neutral stance in deciding whether an individual is a speaker and thinker, and whether a pair is better off in that respect than a solitaire. The neutral point of view is that of someone who observes the solitaire, and then the pair, and tries to ascertain whether, on the basis of this observation, determinate meanings and the concept of objectivity can be attributed to them. Thus, we are back to the days of radical interpretation with a vengeance - with a vengeance, because we are back to the days when reflecting on radical interpretation was understood simply as reflecting on what it would take to interpret an alien speaker from scratch on the exclusive basis of her behaviour in a given environment. And thus we are back to the days when it was assumed that mere interpretability, and not actual interpretation, is required for someone to have a language and thoughts (since interpretability is sufficient to meet the publicity constraint). But there is good reason to believe that the claim that only interpretability is required was never Davidson's. He in fact has said that radical interpretation is an instance of triangulation. ${ }^{15}$ For the triangulation argument shows that radical interpretation cannot succeed without triangulation and so actual interpretation. It cannot succeed because, in a nutshell, solving the aspect problem, which the radical interpreter must obviously do, requires triangulation. Now, to the details of Ludwig's misunderstanding.

Ludwig writes: "The rules of the game are that we have to make sense of [the solitaire's] having determinate thought contents and (for the whole package) the concept of objectivity in terms of objective features of its environment and its interactions with them." ${ }^{16}$ Right, but we must keep in mind that the solitaire herself must contribute to the determination of the meaning of her thoughts and utterances. And we must keep in mind that this requires her to have the concept of objectivity. So, we want a story about her, from her point of view, that makes intelligible how she can achieve all of this. Imagining someone who is interpretable, on the spot, as Ludwig imagines solitaire Robin being, to my mind question-beggingly, will not cut it, as we are to imagine someone who does

15 See Davidson, “Comments on Karlovy Vary Papers,” p. 294.

16 Ludwig, "Triangulating on Thought and Norms," Section 3.2. All references to Ludwig are to this text. 
just what we do, including uttering sounds readily interpretable as English, without being given any clue of what about her made this possession of a language possible. In short, the relevant question here is not just "whether RP [Robin's pattern of behaviour] suffices to determine an acceptably determinate interpretation scheme." ${ }^{17}$ Moreover, in any case, the answer to this is that it does not suffice, as determinate interpretation requires triangulation. This is in fact true both of the solitaire and of Robin and Friday. As long as we cannot interact with the pair, we cannot interpret them, for we cannot solve the aspect problem, and so we cannot know what the causes of their utterances are. ${ }^{18}$

Ludwig would be happy enough to grant that the solitaire and the pair pose the same problem - it just goes to show, he would say, that adding someone to the picture in the solitaire scenario makes no difference. However, it does (see ix. and x.). But Ludwig has a worry about how I think it does. He complains that my description of the solitaire, about whom I ask how she could draw an objective line between what is the case and what seems to her to be the case, grants in effect that she can raise the question and so can already make the relevant distinction because she can think. ${ }^{19}$ This is not quite right. The quest, to be stressed, is to make intelligible the idea that the solitaire has the resources to have the concept of objectivity. The way I proceed to try to make intelligible this idea is by initially granting her thoughts, but of course not the concept, for this would lead us nowhere. I am just granting what many are willing to grant, namely, the presence of thoughts without possession of the concept of objectivity. The question then is whether the solitaire could have this concept because she has disagreed with herself and has settled with herself the disagreement. And the answer is that she could not do this objectively. So, she could not have the concept of objectivity. And so she could not have thoughts after all. The argument has the form of a reductio.

Ludwig's mistake with the triangulators is similar. The question, again, is not "what about the behaviour pattern in the case with two individuals, described neutrally with respect to whether those exhibiting it have thoughts and the concept of objectivity, adds something crucially missing in the case of the solitaire." ${ }^{20}$ Rather, we start by granting them thoughts, but here it turns out that we can make sense of their having the concept because we can make sense of their settling disputes objectively. What makes all of this hard to accept and hard to express to begin with is that we cannot tell the story from a purely detached third-person point of view. We can only tell the story from within, so to speak. This is part and parcel of Davidson's non-reductionism. The full answer to the question of what it is for thoughts and utterances to mean what they do can be

\footnotetext{
17 Ludwig, Section 3.2.

18 Here the point is purely epistemic. Robin and Friday may well have a language, but we could not know what it is without triangulating with them. 
provided only by considering the linguistic interactions in which people engage. It cannot be answered simply by addressing the question of "whether the objective facts about the solitaire's behaviour provide a pattern sufficient for the application of the concept of thought and attribution of the concept of error."21

Ludwig concludes by saying that "[p]rovided that we are willing to think of solitaire Robin as having a language as well as thought, Davidson could still maintain just about everything he wants to." 22 But, in order to think this, we must be told how the problems Davidson thinks need to be solved by the would-be thinker and speaker have been solved, or why the problems need not be solved. And Ludwig has done neither.

\section{Reply to Miller}

Miller poses four challenges. The first one is to my claim that it follows from the triangulation argument that meaning is normative in a more robust way than the trivial one, according to which meaningful expressions must be governed by conditions of correct application. The second is to my claim that Saul Kripke's solution to the sceptical problem about meaning embodied in Wittgenstein's paradox is communitarian. The third is to my failure to explain how Davidson's nonreductionism can do justice both to the first-person epistemology of meaning and to its disposition-like theoreticity. The fourth is to my claim that Davidson's non-reductionism is non-quietist. To address the last three challenges properly would require considerably more space than I have here. It would require a thorough review of Wright's views, which I do not discuss in the book, and of Kripke's views, the interpretation of which continues to be highly debated. However, here is the gist of my responses. I take up the challenges in reverse order.

1. The last challenge is in effect to get clearer on the triangulation argument itself, in particular, on whether anything more illuminating can be said about the meaning-determining triangulation process. Miller asks: "can we spell out in detail what linguistic triangulation involves in a way that avoids a trivialising reading like 'a process that ensures that $\mathrm{S}$ means what he says he means'?" ${ }^{, 23} \mathrm{Can}$ we improve on what I say in the following (quoted by Miller) ${ }^{24}$ :

[T] he question of what one means by one's utterances and what thoughts one has can be answered only within a semantic context, by saying that one means or thinks such and such or so and so.

It is ... what she thinks her terms mean, that determines what they do mean.

21 Ludwig, Section 3.2.

22 Ludwig, Section 3.2.

23 Miller, "Verheggen on Davidson and Kripke on Meaning and Rule-Following," Section 4. Unless otherwise indicated, all references to Miller are to this text.

24 Miller, Section 4. 
To begin with, note that, in the first quotation, I describe, not what determines what the speaker means by her utterances, but what it takes to answer the question of what someone's utterances mean. Ultimately, in order to answer this question, we must say that the speaker means such and such by the utterances, as opposed merely to, for example, the speaker produces the utterances in such and such circumstances. The second quotation is also slightly misleading, taken out of context. What I say there is meant as an answer to a claim I once consid$\operatorname{ered}^{25}$ (and subsequently rejected), according to which someone who does not have the concept of objectivity could still have a language "in so far as the meanings of her utterances could be fixed by another person with whom she interacts and who has the concept." 26 I go on to argue that, unless the speaker herself can distinguish between the correct and incorrect applications of her terms, "we cannot really distinguish her from an automaton. It is what she thinks the distinction is, and so what she thinks her terms mean, that determines what they do mean. No one else can do this for her." 27 Still, the question is, what puts us in a position to say that a speaker means such and such? What puts the speaker in a position to draw the distinctions she draws, to think that she means what she does?

We of course cannot specify non-circular sufficient conditions for someone's meaning the particular thing she does by a particular word (of course, for some words, we could specify what they mean by using other words, but we could not do this for all words). Thus, we cannot describe in non-semantic detail the particular process that leads to a speaker's meaning what she does by any of her words, how the aspect problem was solved in any particular case. Anything short of saying that she means such and such would not suffice to determine that she means it. We can, however, specify necessary conditions for someone's words meaning what they do. That is, we can say something about the process that makes it possible that a speaker means what she does by a particular word. So, in order for us to be able to conclude that a speaker means table by 'table', and in order for the speaker to be in a position to think that this is what she means, she must have participated in numerous linguistic triangular situations. These typically have involved causal interactions with tables and other speakers, as well as interactions with other features of the world and with others using other words. These interactions also have involved her recognizing, through disagreements about her and others' linguistic responses to features of the world around them, the distinction between how things are and how they appear to be. The process through which the meanings of her words get to be fixed will also vary from speaker to speaker. Thus, one could mean table by 'table' without

\footnotetext{
25 See Verheggen, "Triangulating with Davidson."

26 Myers and Verheggen, Donald Davidson's Triangulation Argument: A Philosophical Inquiry, p. 39, fn. 58. Unless otherwise indicated, all references to Myers and Verheggen are to this text.

Myers and Verheggen, p. 40, fn. 58.
} 
ever having triangulated on tables. Still, a speaker could not mean table by 'table' if the meaning of some of her words had not been fixed through triangulation. Now, this account may not be altogether satisfying, as non-reductionist accounts are bound not to be. But it seems to me that the necessary conditions it sets on meaningfulness are far from trivial; indeed, they are far from uncontroversial.

As to Miller's question of how Davidson's account compares with Wright's, I take it that Wright's account, being non-reductionist, also cannot provide noncircular sufficient conditions for someone meaning what she does by her words. But I am not sure what Wright takes to be the necessary conditions. His C-conditions for making judgements about the contents of one's intentions (and presumably meaningful utterances) are, Miller writes, "roughly as follows: The subject $S$ is not lying, is prey to no material self-deception, is not making a simple slip of the tongue, has an adequate grasp of the concepts requisite for the expression of the intention, and is adequately attentive to the question of the content of his intention." 28 But this says nothing about what, according to Wright, puts a speaker in a position to judge that she has such and such an intention or means such and such by an expression. What determines the content of that judgement? Is there any talk, in Wright's writings, of a speaker interacting with her environment, and with other people, that would be part of a constructive account of meaning? Indeed, is Wright here not simply a quietist? The nonquietist side of his non-reductionism seems to have little to do with answering Davidson's question of what it is for words to mean what they do and what it is for thoughts, intentions, etc., to have the content they have. Rather, it has to do with his answering another question, which is in effect the next challenge posed by Miller, the question, that is, of "how is it possible for there to be states that simultaneously exhibit first-person authority and disposition-like theoreticity?", according to which ascriptions of meaning (quoting Wright) "have to answer, after the fashion of dispositions, to what one says and does in situations so far unconsidered." 29 What is Davidson's answer to this question?

2. To begin with, it should be clear that Davidson does advocate first-person authority. He in fact thinks that his externalist account of meaning is superior to Hilary Putnam's and Tyler Burge's ${ }^{30}$ in part because it does not threaten firstperson authority in the way in which he takes their accounts to threaten it. It does not because, on Davidson's account, only beliefs or attitudes a speaker has are allowed to contribute to the determination of the meaning of her words. Thus, if she fails to have any belief about, say, the microstructure of water, or the medical

28 Miller, Philosophy of Language, p. 275.

29 Miller, Section 3.

30 See Putnam, "The Meaning of "Meaning,," and Burge, "Individualism and the Mental." 
definition of 'arthritis', these cannot contribute to determining what she means by 'water' or 'arthritis' in the way Putnam and Burge think that they can. ${ }^{31}$ Aside from this, Davidson has said little about first-person authority in his writings on triangulation. But it should be obvious that his account makes room for it, since the speaker, in effect, creates the meanings of her words and thoughts through the triangulating interactions in which she engages. It makes no sense to say that her self-knowledge is inferential or that she could be systematically wrong about what she means by her words or about what she thinks (which is not to say that she is infallible). Now, this may well sound like Wright's solution to the problem of the first-person epistemology of meaning, since he, too, believes that the meanings of someone's words and thoughts are determined by what she judges them to mean. But there is an important difference between Davidson's and Wright's views (over and above that previously noted). For Davidson, once the meanings of someone's words are fixed, the judgement she may then make about what she means passes what Wright calls the "order-of-determination test" 32 in that it tracks, rather than determines, the truth about what she means. ${ }^{33}$

Davidson, like John McDowell, believes that our meaning what we do by our words determines which applications are correct or not, independently of our judging that they are so. His siding with McDowell here is not something Davidson ever makes explicit. ${ }^{34}$ But I believe that this is his view, and it is certainly one I would want to defend, for, like McDowell, I fail to see how Wright's idea of judgement-dependence could be reconciled with the idea that meaningful expressions must have conditions of correct application. If my judgements about what I mean do not track the truth about what I mean, but rather determine it, how can what I mean not depend entirely on what I judge? Thus, since judging what one's words mean is in effect judging what their conditions of correct application are, how can the question of whether these conditions are fulfilled or not in any particular case be answered independently of what I judge? And so how can they be such that it is not the case that whatever I say is correct in fact is so, thereby undermining the distinction between correct and incorrect applications, and thus meaningfulness? In short, Wright may be able to account

31 See Davidson, "Knowing One's Own Mind."

32 Wright, "Wittgenstein's Rule-Following Considerations and the Central Project of Theoretical Linguistics," p. 192.

33 Note that, though what one means by one's words is not judgement-dependent in the way envisaged by Wright, neither is it judgement-impervious, so to speak, in so far as to mean what one does by a word involves an ongoing commitment to using it in certain ways.

34 Though he did complain about Wright's (and others') anti-realism in "Epistemology and Truth." For McDowell's views, see, e.g., "Intentionality and Interiority in Wittgenstein." 
for the disposition-like theoreticity of meaning, but perhaps only at the cost of not being able to account for its objectivity.

However, there remains the question of how Davidson can account for the disposition-like theoreticity of meaning. As I understand Kripke, to whom Wright is reacting, the problem for the non-reductionist is to explain how an irreducible or "primitive" meaning-state, which "would have to be a finite object, contained in our finite minds" 35 could classify so far unconsidered applications, indeed, a potential infinity of them, as correct or incorrect. How can our finite minds "give rules that are supposed to apply to an infinity of cases?"36 "Can we conceive of a finite state which could not be interpreted in a [deviant] way?"37 If we cannot, if a finite state can always be interpreted in such a way that, however one applies a word, the application is correct or not, as the case may be, then no finite state could, after all, constitute what one means by a word. Fortunately, Davidson, no more than Wright, does not share this view of meaning. For Davidson, to mean something by a word is not to have in one's mind an entity called meaning. Rather, it is to have a capacity for producing meaningful utterances and for taking these utterances to be responses to an objective world, and, therefore, for taking them to be correct or incorrect. It is in the very nature of this capacity that it classifies uses of words as correct or incorrect. And, again, given the process through which a speaker has endowed her words with meaning, it is a capacity over the exercise of which she, by and large, has authority. Against this, it might be protested that, since a speaker does not keep (re)creating the meanings of her words, since she does not keep (re)creating their conditions of correct application, she may lose the authority she initially had. But the capacity that constitutes a speaker's meaning what she does by her words is one that she keeps exercising, one that she keeps in the front of her mind, so to speak, as she keeps using the words. Thus, it makes no sense to think of losing the capacity to distinguish between the correct and incorrect applications of all the words in her repertoire. This is not to say that she could not lose it for any given word, which may happen if she stops using the word, just as one may lose the capacity to ski if one no longer ever engages in it. But it seems to me that there is no mystery surrounding the claim that, by and large, speakers are authoritative in their exercise of this capacity.

In short, the similarity between Davidson's and Wright's accounts of meaning is only superficial. Unlike Wright, Davidson provides a substantive answer to the question of what it is for words to mean what they do (and for judgements to have the content they have). And he rejects the claim that meaning is judgement-dependent in the way Wright understands it. But I believe that

35 Kripke, Wittgenstein on Rules and Private Language, p. 52. All references to Kripke are to this text.

36 Kripke, p. 54.

37 Kripke, p. 52. 
Davidson's account can reconcile the first-person epistemology of meaning and its disposition-like theoreticity, though I have only sketched how this reconciliation could be achieved.

3. I turn to Miller's comment on Davidson and Kripke. First, Miller complains that I am in danger of attributing to Kripke a straight, rather than sceptical, communitarian solution to the problem he finds in Wittgenstein's writings on rulefollowing. This certainly was not my intention, though I admit my way of expressing the solution is misleading. Thus, instead of saying "the meanings of a speaker's words are determined by what the members of her community mean by those words. Correct applications are applications that conform to the conditions of correctness at play in her community," 38 I should have said that ascriptions of meaning to a speaker's words are based on the speaker's inclinations to use these words in ways that agree with her community's inclinations to use them. The distinction between correct and incorrect applications of an individual's words (which, I take it, the sceptical solution is obliged to account for) is based on how the distinction is drawn in the speaker's community. By putting it this way, there is no danger, I hope, of understanding my interpretation of Kripke's solution as straight, that is, as maintaining that the meaningdetermining facts that Kripke argues do not exist have after all been found. Miller is right in observing that community facts would be as subject to the sceptical problem as those considered by Kripke's sceptic.

Second, Miller suggests that, once properly understood, Kripke's sceptical solution $^{39}$ is consistent with Davidson's interpersonal view of meaning. For, instead of cashing out the assertibility condition for an ascription of meaning to a speaker's expression in terms of her sharing the inclinations her community does have to use that expression, we could cash it out in terms of her sharing the inclinations the community would have to use the expression were it inclined to use the expression in ways that agree with the speaker's inclinations. This strikes me as a reasonable suggestion, though evidence for it is hard to find in Kripke's text; he writes, for instance, that "[w]e say of someone else that he follows a certain rule [means what he does by an expression] when his responses [applications] agree with our own and deny it when they do not." 40 Of course, Miller's suggestion makes Kripke's sceptical solution consistent only with the interpersonal aspect of Davidson's view. For one thing, Davidson thinks that ascriptions of meaning must be cashed out, not in terms of assertibility conditions, but in terms of truth conditions (though Davidson's truth-conditional view is different from the classical realist truth-conditional view rejected by

\footnotetext{
38 Miller, Section 2.

39 Throughout, 'Kripke' stands for 'Kripke's Wittgenstein,' as Kripke did not want to commit himself to any view.

40

Kripke, p. 92.
} 
Kripke on behalf of the sceptic). For another, it continues to be debated whether Kripke's sceptical solution is reductionist or not. Miller seems to suggest that it is, as he mentions "the need to eliminate reference to community judgement"41 in the description of the assertibility conditions of meaning ascriptions. I think it is not. Indeed, I think that Kripke is a quietist about meaning.

According to the communitarian version of Kripke's sceptical solution, what licenses our ascriptions of meaning to someone's expression is that she is inclined to use it in the same way as the members of her community. According to the interpersonal version, what licenses our ascriptions of meaning to someone's expression is that she is inclined to use it in the same way as the community would use it were it to judge that it means what the speaker means by the expression. In each case it seems to me that the pressing question is: what is it about the community's inclinations, actual or potential, to use its expressions in certain ways that licenses us to ascribe them the meanings we do? What is it about them that licenses us to distinguish between correct and incorrect applications in some ways rather than others? On both the communitarian and the interpersonal versions of the solution, agreement, actual or potential, in use is involved, but, in both cases, it is presumably, as Kripke says, "brute" agreement, ${ }^{42}$ with no indication of how this agreement is reached, which would be part of a constructive account of meaning. In short, it seems to me that Kripke does not give us much of a philosophical account of meaning. ${ }^{43}$ Interestingly, the interpersonal version of Kripke's sceptical solution makes it more vivid what is missing. For, on the communitarian version, we may take it for granted what meanings are ascribed to the community's expressions, and we understand, in light of this, what legitimizes our ascriptions of meaning to an individual speaker's expressions. However, on the interpersonal version, we have no clue where to begin. This is precisely what Davidson supplies: an account according to which, importantly, interpersonal externalism, that is, the social side of the account, is only part of the story and is in fact needed to secure perceptual externalism, that is, the physical side of the account. I am not saying that Kripke could not provide an account along these lines, but he has not.

4. Finally, I turn to Miller's comment on normativity. Most everyone believes that meaning is what I call trivially normative in that meaningful expressions must have conditions of correct application. The question is: is meaning normative in any sense other than the trivial one? I believe that it follows from the triangulation argument that meaning is normative in two further, more robust ways. First, it is normative in the sense that, unless one has normative attitudes

\footnotetext{
41 Miller, Section 2.

42 Kripke, p. 97.

43 For more on Kripke's quietism, see Sultanescu and Verheggen, "Davidson's Answer to Kripke's Sceptic."
} 
toward one's own and others' uses of words, that is, unless one actually distinguishes, on some occasions at least, between the correct and incorrect applications that one and others make of words, one cannot use words meaningfully. Second, meaning is normative in what has been called a meaning-engendered way, according to which statements about what a speaker means by her words have normative implications about how she should use her words. I do not believe that these implications are categorical. (I do not believe that, for example, if one means chair by 'chair', one has a prima facie obligation to apply 'chair' to an object only if the object is a chair.) But I believe that, hypothetical though they may be, these implications are essential to meaning in a way that the hypothetical implications that follow from statements about natural facts are not essential to these facts. To see this, I turn to Miller's objections.

First, he says, "the argument seems to depend on some principle to the effect that if I have a say in the constitution of a fact, that fact cannot remain intact if I subsequently become indifferent to it." 44 However, he asks: is it not the case that some agent-constituted facts are less sensitive? Take promises, which surely are facts I contribute to constituting. If some subsequent desire leads me to break a promise I made, we still want to say that the promise remains intact. Similarly, Miller continues, "couldn't it be that the way in which I contribute to the constitution of the fact that I mean sunny by 'sunny' leaves it intact even if I subsequently no longer desire to produce meaningful utterances", 45 that is, I take it, even if I no longer desire to utter 'sunny' in accordance with its conditions of correct application?

Matters are a little tricky here, for it is not clear how the analogy, if any, between promises and statements about the meaning of one's expressions call them meaning facts - should be understood. For one thing, if the analogy is between my making a promise to myself and my stating what I mean by an expression, as, strictly speaking, it should be, then it looks as if promises and meaning facts are in the same boat, though not Miller's boat, for if I become indifferent to a promise I made to myself, the promise (at least arguably) does not remain intact, any more than the meaning fact remains intact if I become indifferent to it. That is, in either case, I am no longer bound by the fact. ${ }^{46}$ On the other hand, if the promise is made to someone else, then there is no doubt that it remains intact even if I become indifferent to it. But this indicates that the prescriptions that follow from promises made to others are categorical, not contingent on any particular desires one has, unlike the prescriptions that follow from statements about meaning. Let me elaborate on the disanalogy.

On the one hand, if I promise to visit you in Chicago as soon as it is sunny, but disown my promise when the sun arrives, my promise does not disappear, and I am

\footnotetext{
44 Miller, Section 1.

45 Miller, Section 1.

46 Thanks to Sam Steadman for calling my attention to this possible analogy.
} 
still bound by it. On the other hand, if I no longer desire to use 'sunny' in the way dictated by the conditions of correctness that govern its applications, then the word ceases to mean sunny for me. This does not entail that I did not previously mean sunny by 'sunny', but unlike in the case of a promise made to someone else, this fact is not binding on me now. The statement about what 'sunny' means for me has become false. My meaning now what I did previously is entirely contingent on my continuing to desire to use the word in certain ways, to take certain conditions of correctness to be governing its applications. So, I do not think that Miller has shown that the principle to the effect that at least some agent-constituted facts do not remain intact if agents subsequently become indifferent to them is not a good principle. But Miller may still insist that, even if there is a disanalogy between promises and meaning facts, this does not show that meaning is normative in any sense over and above the trivial. So, I turn to his second objection.

Miller writes: "the statement 'If you want to go to the largest grocer in Oxford, you ought to go to Grimbly Hughes,' although it contains an 'ought,' is actually equivalent to the purely descriptive statement 'Grimbly Hughes is the largest grocer in Oxford.' So, hypothetical prescriptions don't generate genuine normativity. ${ }^{\circ 7}$ Presumably, he wants us to compare this with the statement "if I mean chair by 'chair' then, if I want to tell the truth, I ought to apply 'chair' to an object only if the object is a chair", and then say that this is equivalent to the purely descriptive statement "I apply 'chair' correctly to an object only if the object is a chair", thereby showing that the hypothetical prescriptions that follow from statements about meaning do not make meaning genuinely normative. There seems to be no denying here that, in both cases, the prescriptive statements follow from the descriptive ones (and vice versa); and, in both cases, if the prescriptive statements do not follow, the descriptive statements become false (and vice versa). I am still inclined to say, however, that there is an important disanalogy between natural facts and meaning facts. For, in the former case, if the hypothetical implications do not apply to me because, say, I do not care about going to the largest grocer in Oxford, the statements about natural facts remain true, whereas, in the latter case, if the hypothetical implications do not apply to me, because, say, I no longer care what I mean by 'chair', the statements about meaning become false. It is my being committed to the hypothetical prescriptions that makes it the case that I mean what I do.

Perhaps another way to understand that there is a disanalogy is by noting first that there is a difference between the content of prescriptive statements and the content of their equivalent descriptive statements. Obviously, prescriptive statements say something about how we should act given that certain facts obtain. However, a natural fact is what it is independently of anyone engaging in the behaviour dictated by the hypothetical prescriptions that our desires might generate regarding that fact. Not so, I believe, of the meaning fact. It is the behaviour

47 Miller, Section 1. 
dictated by the hypothetical prescriptions that makes the meaning fact the fact that it is. Grimbly Hughes is the largest grocer in Oxford, regardless of whether anyone wants to go to the largest grocer in Oxford. But I do not apply 'chair' correctly to an object only if the object is a chair, if I do not care what I mean by 'chair'.

Miller ends by conceding that " $[\mathrm{m}]$ eaning could indeed be essentially hypothetically prescriptive but still fail to be normative in any sense beyond the trivial." 48 To be sure, if the only sense in which meaning can be genuinely normative is the categorical one, then meaning can only be trivially normative. One way to understand what I am suggesting here is that trivial normativity, that is, meaningful expressions having conditions of correct application, requires hypothetical normativity, that is, commitments to using expressions in certain ways, ways which are essential to these expressions meaning what they do. This is another way of saying that the speaker plays an essential role in determining the meaning, and conditions of correct application, of her expressions, which is one of the central tenets of the triangulation argument.

\section{Acknowledgements}

I am very grateful to Olivia Sultanescu for organizing the authors-meet-critics symposium at the 2018 meeting of the Canadian Philosophical Association in Montreal, for editing this special issue of Dialogue, and for commenting on an earlier draft of my replies.

48 Miller, Section 1.

\section{References}

Burge, Tyler

1979 "Individualism and the Mental." Midwest Studies in Philosophy 4(1): 73-121.

Davidson, Donald

1975 “Thought and Talk," in Davidson 1984, pp. 155-170.

Davidson, Donald

1984 Inquiries into Truth and Interpretation. Oxford: Clarendon Press.

Davidson, Donald

1987 "Knowing One's Own Mind," in Davidson 2001, pp. 15-38.

Davidson, Donald

1988 "Epistemology and Truth," in Davidson 2001a, pp. 177-191.

Davidson, Donald

1990 "The Structure and Content of Truth." Journal of Philosophy 87(6): 279-329.

Davidson, Donald

1991 “Epistemology Externalized," in Davidson 2001a, pp. 193-204.

Davidson, Donald

1992 "The Second Person," in Davidson 2001a, pp. 107-121. 
Davidson, Donald

1999 "The Emergence of Thought," in Davidson 2001a, pp. 123-134.

Davidson, Donald

2001a Subjective, Intersubjective, Objective. Oxford: Clarendon Press.

Davidson, Donald

2001b "Externalisms," in Kotatko et al. 2001, pp. 1-16.

Davidson, Donald

2001c “Comments on Karlovy Vary Papers," in Kotatko et al. 2001, pp. 285-307.

Davidson, Donald

2003 "Responses to Barry Stroud, John McDowell, and Tyler Burge." Philosophy and Phenomenological Research 67(3): 691-699.

Kotatko, Petr, Peter Pagin, and Gabriel Segal, eds.

2001 Interpreting Davidson. Stanford: Center for the Study of Language and Information.

Kripke, Saul

1982 Wittgenstein on Rules and Private Language. Cambridge, MA: Harvard University Press.

McDowell, John

1991 "Intentionality and Interiority in Wittgenstein," in his Meaning, Value, and Reality. Cambridge, MA: Harvard University Press (1998), pp. 297-321.

Miller, Alexander

2018 Philosophy of Language. $3^{\text {rd }}$ edition. London and New York: Routledge.

Myers, Robert H., and Claudine Verheggen

2016 Donald Davidson's Triangulation Argument: A Philosophical Inquiry. New York: Routledge.

Putnam, Hilary

1975 "The Meaning of 'Meaning'," in his Mind, Language, and Reality. Cambridge: Cambridge University Press, pp. 215-271.

Sultanescu, Olivia, and Claudine Verheggen

2019 “Davidson's Answer to Kripke's Sceptic." Journal for the History of Analytical Philosophy 7(2): 8-28.

Verheggen, Claudine

2007 “Triangulating with Davidson.” The Philosophical Quarterly 57(226): 96-103.

Wright, Crispin

1986 "Does Philosophical Investigations $\S \S 258-60$ Suggest a Cogent against Private Language?," in his Rails to Infinity, pp. 223-290.

Wright, Crispin

1989 "Wittgenstein's Rule-Following Considerations and the Central Project of Linguistics," in his Rails to Infinity, pp. 170-213.

Wright, Crispin

2001 Rails to Infinity. Cambridge, MA: Harvard University Press. 